\title{
GROWTH AND CHARACTERIZATION OF L-LYSINE MONOHYDROCHLORIDE DIHYDRATE CRYSTALS
}

\author{
Carvalho, J. O. ${ }^{1}{ }^{2}$, , ; Façanha Filho, P. F. ${ }^{1}$; dos Santos, A. O. ${ }^{1}$; de Moura, G. M. ${ }^{1 \text {; }}$ \\ Rodrigues, J. L. ${ }^{1}$ \\ ${ }^{1}$ Universidade Federal do Maranhão, Imperatriz, Maranhão, Brasil \\ ${ }^{2}$ Instituto Federal do Tocantins, Araguaína, Tocantins, Brasil
}

*jhonatan.carvalho@hotmail.com

\begin{abstract}
Amino acid single crystals have been attracted researchers in recent years due their applications as second harmonic generator. Therefore, it is important to study this kind of material when submitted to high temperature. The goal of this work is to produce the semiorganic single crystals of L-lysine Monohydrochloride Dihydrate ( $\mathrm{LMHCl}$ ) and verify its thermal stability. $\mathrm{LMHCl}$ single crystals were grown by solvent slow evaporation technique at a constant temperature of $25^{\circ} \mathrm{C}$. X-ray diffraction (XRD) and Rietveld refinement were performed for identification of the material at room temperature. Raman scattering measurements at room temperature were carried out to identify the vibrational normal modes of the crystal. Thermal stability was investigated by DSC and DTA-TGA. In addition, it was performed XRD with temperature variation, in order to confirm any phase transition. LMHCL crystal belongs to monoclinic space group with two molecules per cell unit. The Rietveld refinement presented good results with $R_{w p}=$ 14,73 and $R_{p}=10,54$. Furthermore, most vibrational normal modes were tentatively assigned by Raman spectroscopy. Thermal analysis results have shown that the material loses water molecules above $60^{\circ} \mathrm{C}$. XRD with temperature is in concordance with the thermal analysis and the phase transition above $60^{\circ} \mathrm{C}$. Therefore, the material is stable up to $60{ }^{\circ} \mathrm{C}$, whose phase transition is confirmed by XRD and the role of the water molecules on structural stability of the crystal is analyzed.
\end{abstract}

